\title{
Psychodermatology: An Overview of History, Concept, Classification, and Current Status
}

\author{
Ravindra Neelakanthappa Munoli@
}

\begin{abstract}
Psychodermatology is an evolving discipline of medicine with an interface of dermatology and psychiatry. Current psychodermatology relies on understanding that biological, psychological, and social factors play roles in the disease etiopathogenesis. These interactions can be seen over the entire disease course. Recent research addressed the embryological and physiological connections between skin and nervous system, which get reflected in many dermatoses. Various classifications have evolved to understand psychodermatological disorders but there is lack of consensus on definition and classification. Though various models of clinics have shaped up, a holistic approach by liaison between psychiatrist, dermatologist, and psychologist will be ideal to address these. Current review addresses history and evolution of psychodermatology, defines psychodermatology, discusses classification, and explores pathophysiological aspects.

Keywords: Classification in psychodermatology, Definition of psychodermatology, History of psychodermatology, Psychodermatology, Psychodermatology clinic, Psychodermatology in India, Stress and psychodermatology.

Indian Journal of Private Psychiatry (2020): 10.5005/jp-journals-10067-0067
\end{abstract}

\section{INTRODUCTION}

Skin is the largest organ of the body. It is the "first point of contact" while meeting and it serves as a barricade between person's inner world and the external world. ${ }^{1}$ It is considered as the "organ of expression" also. ${ }^{2}$ Psychological facet of skin was described by psychoanalyst Didier Anzieu as "psychological shell" and coined the term "Skin Ego", in which physiological skin functions were compared with the psychological representations of ego and the idea of "self" in children must be developed by them from their own body surface. ${ }^{3}$ The intricacies of skin's relationship with external and internal stimuli are evident by the ways in which the skin can react to both physiological (e.g., a rash caused by an external noxious substance) and psychological (e.g., blushing when embarrassed) events. Impact of dermatoses on a person is multipronged with effects on interpersonal communication and interaction via body, emergence of fear, anxiety, shame, guilt, self-stigma, visual exposition, stigmatization, and sexual dysfunctions. ${ }^{4}$

Literature search was done in PubMed, GoogleScholar, text books with keywords "psychodermatology", "psychocutaneous medicine," "psychopharmacology in dermatology", "psychodermatology India". Review articles and original articles were included in this narrative review.

Psychodermatology can be understood as aspect of dermatology, wherein psychological factors play a significant role in dermatoses. Psychodermatology addresses the biological underpinnings and clinical expression on the platform of link between the skin and the psyche. Embryological origin of skin and brain is same ectoderm and both are regulated by same hormones and neurotransmitters. Nearly $30 \%$ of dermatology patients have psychiatric and psychosocial comorbidities ${ }^{5}$ and these contribute to overall disability of dermatoses. ${ }^{6}$

Psychiatric issues complicate morbidity of dermatoses by affecting their physical, social, emotional and occupational domains which in turn lead to disability, nonadherence to treatment, and hinder better prognosis. ${ }^{7,8}$ Addressing these issues was beneficial for psychologic stress reduction and improved outcome. ${ }^{8}$ These
Department of Psychiatry, Kasturba Medical College, Manipal Academy of Higher Education, Manipal, Karnataka, India

Corresponding Author: Ravindra N Munoli, Department of Psychiatry, Kasturba Medical College, Manipal Academy of Higher Education, Manipal, Karnataka, India, Phone: +91 9972028881, e-mail: ravindra. nm@hotmail.com

How to cite this article: Munoli RN. Psychodermatology: An Overview of History, Concept, Classification, and Current Status. Ind J Priv Psychiatry 2020;14(2):85-91.

Source of support: Nil

Conflict of interest: None

further strengthen the notion of bidirectional relationship between psychiatric and dermatologic disorders. ${ }^{9}$

\section{Definition}

Psychodermatology is conceptualized as a merge between psychiatry and dermatology which addresses the role of psychosocial stress in the exacerbation or chronicity of dermatologic diseases. ${ }^{10,11}$ Further it is conceptualized as a discipline which analyses comorbid psychiatric comorbidities with dermatologic conditions and the role of adjuvant psychopharmacological, psychosocial, or psychotherapeutic interventions. ${ }^{12,13}$

There is no standard universally accepted definition of psychodermatology as such. Author defines psychodermatology or psychocutaneous medicine as: "a branch of medicine which addresses dermatoses or physiological changes in skin, in which psychosocial factors play role in etiopathogenesis, progression, exacerbation, treatment or prognosis; further it addresses all dermatoses, in which psychological disorders can be seen as comorbidities, either as primary conditions or as secondary conditions due to dermatoses or as treatment (with dermatological treatment or with psychotropics) emergent conditions and all of these will require comprehensive psychocutaneous approach of assessment and intervention." 


\section{History and GROWTH OF Psychodermatology as a Discipline}

The first description of psychodermatologic case vignette can be traced to $1700 \mathrm{BCE}$, when a prince in Persia had developed psoriasis due to anxieties about succession to royal throne. ${ }^{14} \mathrm{Greek}$ philosopher Hippocrates (460-377 BC) had suggested association between emotional stress and skin disease and reported to cases of hair pulling in response to stress. ${ }^{15}$ Aristoteles believed skin and mind are complementary entities and are inseparable. ${ }^{16}$

The description where Buddha treated a lady of her socially embarrassing and debilitating skin disease by teaching her to control her anger by mind can be the first example of psychodermatology in Asian subcontinent. ${ }^{17}$ In Charaka Samhita skin has been considered as having relationship with mind and termed it as "Cheetah Samvaayi" and Gayaadas attributed behavioral misconducts as one of the causative factors for skin disease. ${ }^{18}$

Historical descriptions about trichotillomania can be seen in the Bible; ${ }^{19}$ later in Shakespeare's King Lear and Romeo and Juliet. Delusional parasitosis was documented as a condition in 1799 by British dermatologist Robert Willan and later in 1801 by Johann Heinrich Jordens. ${ }^{16}$ In his book "Diseases of the Skin" British dermatologist and surgeon WJE Wilson described "skin neurosis" with explanation of diseases like alopecia aerate, hyperhidrosis, pruritus, delusional infestation and their association with depression/anxiety. ${ }^{20}$ Psychoanalyst Morselli described "dysmorphophobia", psychiatrist Pierre Janet described "I'obsession de la honte du corps" 21 and Sigmund Freud described a case of an aristocrat excessively worried about appearance of his nose. ${ }^{22}$ Karl Ekbom in early 1900s described difference between delusional parasitosis and phobia for insects and termed former as "dermatozoic delusion" (Ekbom's syndrome). ${ }^{16}$

In early 20th century, psychodermatology had gained interest in European medical community and in America it was in infancy. In 1936, Dr Klauder wrote a manuscript on "Psychogenic Aspects of Skin Diseases" and it mentioned "one is more conscious of the skin than any other organ, it occupies an important place in the consciousness, not alone as an abstract idea, but because it is the site of many sensations-heat, cold, touch, pain, itching, sexual, and lustful". ${ }^{23}$ Subsequently, many concepts evolved. In 1990, Association for Psychocutaneous Medicine of North America was established and in 1993, the European Society for Dermatology and Psychiatry was established. In 2018, Psychodermatology Association of India was established. ${ }^{24}$ In India, the first psychodermatology liaison clinic started functioning in 2010 in Kasturba Medical College, Manipal with participation of Departments of Dermatology, Psychiatry and Clinical Psychology of India came into existence as late as 2010 in Manipal, Karnataka ${ }^{25}$ then in Faridkot, Punjab. ${ }^{26}$

\section{Classification of Psychodermatological Disorders}

There is no single globally accepted classification and psychodermatological disorders. One classification divides it into two groups: "(1) primary dermatologic disorders caused by or associated with psychiatric comorbidity and (2) primary psychiatric disorders which present with skin diseases or changes." ${ }^{27}$ The reciprocal relationship of psychiatric complications of dermatologic treatments, and vice versa, was not considered. Classification by Reichenberg et al. ${ }^{28}$ categorized them into three groups: "(1) primary dermatologic conditions causing secondary psychiatric conditions,
(2) primary dermatologic conditions exacerbated by stress or psychiatric conditions, and (3) primary psychiatric conditions that manifest as skin concerns. It ignores side effects of the treatments. Classification by Koo et al. ${ }^{29}$ has four groups: "psychophysiological disorders, primary psychiatric disorders, secondary psychiatric disorders, and cutaneous sensory disorders". Recently Ferreira et al. ${ }^{30}$ classified them into "psychophysiological dermatoses, primary psychopathology focused on the skin, cutaneous sensory disorders, and dermatoses or disfiguring skin conditions leading to psychosocial comorbidity". However, psychodermatoses overlapped in different groups in these classifications.

Another recent classification by Ferreira and Jafferany ${ }^{31}$ divided them into three groups:

- Group A: Primary psychodermatological disease: In this group, the primary dermatoses have psychological stress, a psychological mechanism, and/or psychopathology as main elements either for inducing or for worsening, e.g., alopecia areata (AA), atopic dermatitis, chronic spontaneous urticarial, psoriasis, and vitiligo.

- Group B: Primary psychodermatological illness: In this group of dermatoses, there are skin symptoms, with or without secondary self-induced skin lesions (such as excoriations), without a primary dermatosis, e.g., body dysmorphic disorder, delusional infestation, psychogenic pruritus, self-inflicted skin lesions, dysesthesias like burning mouth syndrome, and vulvodynia.

- Group C: Secondary psychodermatological disorder: In this group, psychiatric complications of medications prescribed in dermatology and dermatological consequences of psychotropics are included as follows:

- Secondary dermatologic disease related to psychiatric medications (Table 1)

- Secondary psychiatric illness related to dermatologic medications-examples:

- Depersonalization: minocycline

- Mood disorders: isotretinoin; methotrexate; systemic steroids

- Psychoses: dapsone; hydroxychloroquine

- Sedation and drowsiness: antihistamines skin disease, skin symptoms or mental illness: linked with exogenous factorsdrug reactions connecting dermatology and psychiatry.

\section{Evolving Subspecialties in Psychodermatology}

With ongoing research and liaison among medical branches, multiple subspecialties have shaped up in psychodermmatology, which are mentioned below.

- Pediatric psychodermatology: It addresses psychodermatologic conditions in children and adolescents. ${ }^{32}$

- Geriatric psychodermatology: It addresses psychodermatologic conditions in elderly population and effects of aging on psychodermatological aspects. ${ }^{33}$

- Trichopsychodermatology: This field focuses on psychological and social aspects of hair hair loss and excess of hair in terms of role of stress on hair disorders, addressing stigma/psychological conditions related to hair loss/excess and quality of life impacted by these. ${ }^{34}$

- Psychodermato-oncology: Skin cancer is the most common type of cancer worldwide, and disfigurement, stigma, anxiety, depression, guilt, and fear of death are commonly encountered conditions. This subspecialty addresses psychological impact 
Table 1: Dermatological side effects of psychotropics

\begin{tabular}{|c|c|}
\hline Dermatological condition & Associated psychotropic \\
\hline Acneifrom eruption & Lithium, Escitalopram, Citalopram, Fluoxetine, Fluvoxamine, Paroxetine, Sertraline \\
\hline Alopecia & $\begin{array}{l}\text { Carbamazepine, Lithium, Valproic Acid, Haloperidol, Quetiapine, Citalopram, Fluoxetine, Fluvoxamine, } \\
\text { Paroxetine, Sertraline, Amitriptyline, Clomipramine, Imipramine, Venlafaxine }\end{array}$ \\
\hline Angioedema & Carbamazepine, Amitriptyline, Clomipramine, Desipramine, Imipramine, Bupropion, Trazodone \\
\hline Eczema & Carbamazepine, Lithium \\
\hline Erythema multiforme & Carbamazepine, Lithium, Paroxetine, Sertraline, Bupropion, Trazodone \\
\hline Exanthem & $\begin{array}{l}\text { Risperidone, Alprazolam, Clobazam, Clorazepate, Flurazepam, Tetrazepam, Citalopram, Fluoxetine, } \\
\text { Fluvoxamine, Paroxetine, Sertraline, Amitriptyline, Desipramine, Imipramine, Bupropion, Trazodone }\end{array}$ \\
\hline Hyperhidrosis & Citalopram, Fluoxetine, Venlafaxine \\
\hline Hyperpigmentation & $\begin{array}{l}\text { Aripiprazole, Chlorproethazine, Chlorpromazine, Clozapine, Haloperidol, Olanzapine, Quetiapine, Risperidone, } \\
\text { Thioridazine, Trifluoperazine, Ziprasidone, Citalopram, Fluoxetine, Fluvoxamine, Paroxetine, Sertraline, } \\
\text { Clomipramine, Desipramine, Imipramine }\end{array}$ \\
\hline Lichenoid eruption & Carbamazepine \\
\hline Photosensitivity & $\begin{array}{l}\text { Citalopram, Fluoxetine, Fluvoxamine, Paroxetine, Sertraline, Carbamazepine, Aripiprazole, Chlorpromazine, Halo- } \\
\text { peridol, Olanzapine, Quetiapine, Risperidone,Thioridazine, Trifluoperazine, Ziprasidone, Amitriptyline, Imipramine }\end{array}$ \\
\hline Psoriasisform eruption & Lithium, Fluoxetine, Paroxetine, Trazodone, Venlafaxine \\
\hline Steven-Johnson syndrome & Carbamazepine, Lamotrigine, Venlafaxine \\
\hline Toxic epidermal necrolysis & Carbamazepine, Lamotrigine, Clobazam, Flurazepam \\
\hline Urticaria & $\begin{array}{l}\text { Lithium, Chlorpromazine, Citalopram, Fluoxetine, Fluvoxamine, Paroxetine, Sertraline, Clomipramine, } \\
\text { Imipramine, Trazodone }\end{array}$ \\
\hline
\end{tabular}

of skin cancer and the role of stress in the development of skin cancers. $^{35}$

- Cosmetic psychodermatology: With the surge in interest in cosmetic procedures and associated psychological aspects in recent decades, cosmetic dermatologists felt the need of tailor-made training in basic psychosocial evaluation, cultural understanding, expectations, and previous experiences. ${ }^{36}$

- Tropical psychodermatology: Tropical skin diseases (infectious or noninfectious), associated psychosocial aspects and quality of life are focused in this subspecialty. ${ }^{37}$

- Sports psychodermatology: Psychosocial impact of commonly seen skin conditions in exercise and sports (inflammations, aberrant growths, trauma) on performance is addressed by this subsection. ${ }^{38}$

- Environmental psychodermatology: This explores the interaction between skin, environment, and stressors. ${ }^{39}$

\section{EPIDEMIOLOGY}

In patients visiting dermatology clinics, 30-40\% had associated psychiatric disorders as comorbidity. ${ }^{40-42} \mathrm{~A}$ chart review of 5 years of $2,43,963$ patients revealed that $28.6 \%$ had received at least one psychotropic medication and patients with pruritus and related conditions (46.7\%), urticaria (44.5\%), and hyperhidrosis (32.8\%) had higher rates of concurrent psychotropics. Antidepressants (56.3\%) were most prescribed psychotropics followed anxiolytics (37.1\%). Antidepressants were prescribed for hyperhidrosis (71.2\%), diseases of hair (61.4\%), and psoriasis (59.1\%), and anxiolytic prescriptions were higher in atopic dermatitis (54.3\%). ${ }^{43}$ In Taiwan, a populationbased study showed major depressive disorder in $11.5 \%(n=17086)$ of psoriasis patients. ${ }^{44}$ In a study from Italy, $8.6 \%$ of outpatients (7.2\% of psoriasis and $5.6 \%$ of acne patients) with dermatoses reported suicidal ideation. ${ }^{45}$ Lifetime prevalence of one or more psychiatric disorders of $74 \%(n=22)$ was found in patients with AA in a survey. ${ }^{46}$ In patients with atopic dermatitis, a lifetime prevalence of attention-deficit hyperactive disorder was found to be $12.6 \%$
( $n=959)$ in United States. ${ }^{47}$ In a comparative study of 502 children and adolescents (251 patients and 251 healthy controls), rates of general psychiatric comorbidity, mood disorders, anxiety disorders, and adjustment disorders as per DSM IV were significantly higher in patients than in controls. ${ }^{48}$

\section{Indian Perspective}

In a prospective study of patients visiting psychodermatology clinic out of 236 patients who visited the clinic over 2 years, 86 had psychiatric comorbidity, 144 required psychological interventions and 98 required psychotropics. ${ }^{49}$ Nearly $33 \%$ of the patients attending psychodermatology clinic had psychiatric comorbidity, the commonest being an adjustment disorder. High prevalence of depression $(36.3 \%, n=146)$ and anxiety $(18.4 \%, n=74)$ was seen in dermatology outpatients in a study by Raikhy et al. ${ }^{50}$ In a study in psychocutaneous clinic in north India, 20 (40\%) patients had neurotic excoriations, 13 (26\%) had trichotillomania, and $12(24 \%)$ had delusional parasitosis. ${ }^{26}$ In a study of inpatients of dermatology in Vellore, South India, 9\% of 1,073 patients had psychiatric comorbidities (depression in $39 \%$ and adjustment disorder in $24 \%)$, mostly in patients with chronic urticaria, erythroderma and sexually transmitted infections; further these patients had extended stay and more admissions, especially in those who were receiving systemic corticosteroids. ${ }^{51}$

Psoriasis and vitiligo have received major attention in psychodermatology research in India ${ }^{52}$ and commonly documented psychiatric disorders with these were adjustment disorder, dysthymia, depressive episode, anxiety, and sleep disturbances, ${ }^{53,54}$ alexithymia. ${ }^{55}$ Stressful life events have led to exacerbation of psoriasis in $32 \%$ and chronic urticarial in $22 \%$ patients in a study of 50 patients in Punjab. ${ }^{56}$ Almost $25 \%$ patients with vitiligo had psychiatric comorbidity (adjustment disorder, dysthymia, and depression). ${ }^{57}$ In a comparative study of 50 patients in each group of psoriasis, AA and accompanying persons, 38 and $22 \%$ patients in psoriasis and AA group, respectively, suffered from psychiatric 
disorder, depression was present in 24 and $18 \%$ of patients and 12 and $4 \%$ had anxiety disorders in respective groups. ${ }^{58} \mathrm{~A}$ bidirectional relationship of vitiligo and $A A$ with depression has been established in large scale cohorts. ${ }^{59,60}$ Psychiatric morbidities were significantly higher in psoriasis (47.6\%) when compared to leprosy $(12.2 \%)$ patients, but severity was more in leprosy group..$^{61}$ In another study, relaxation therapy was found to decrease severity of psoriasis and improved quality of life. ${ }^{62}$ Like in psoriasis, pemphigus vulgaris also has psychiatric comorbidities like adjustment disorder, depression, acute and transient psychosis. ${ }^{63}$ In children with atopic dermatitis aged 3 to 9 years, subnormal intelligence and conduct disorders were significantly higher when compared to healthy controls. ${ }^{64}$

Secondary psychiatric and psychophysiological conditions are common than the primary psychiatric conditions, and delusions of parasitosis are commonly encountered in practice. Trichotillomania had $1.24 \%$ incidence of 1,610 patients seen in child and adolescent clinic over 6 years in Chandigarh, and habit reversal was useful as a treatment modality. ${ }^{65}$

\section{Pathophysiology of Psychodermatological Disorders}

Skin, psyche, and immune system have ontogenic, anatomical, and physicological connections. Origin of the skin and nervous system with same germinal layer and neuroectoderm results in dense network of free nerve endings in the skin and this link is the basis for psychoneuroendocrinoimmunological mechanisms involved in the pathogenesis of dermatoses.

\section{Psychoanalytical UnderpinNings}

Developmental psychology postulates that a very early tactile phase is of importance for the development of person's identity. Dermatoses can be associated with early attachment disorders. It can occur during development of early childhood cognition when dealing with a genetic dermatosis, and during the development of self via "psychoanalytical dialogue with the skin." ${ }^{66}$ Some dermatoses which exist even before the identity formation (e.g., port wine stains and hairy nevi) rarely lead to psychosocial problems as the patients can accommodate the defect into their body image/identity. However, when skin lesions occur later, like scars, vitiligo lesions, these will lead to body image disorders. Conflicts in psychological closeness-distance play role in dermatoses in cases like atopic dermatitis. ${ }^{67,68} \mathrm{~A}$ theory explains that mother will pay excessive attention to the child due to uncontrollable pruritus but this excessive attention can reach a fatigue state and uncertainty of progression of dermatoses may result in a (more or less) subliminal aggression in mother. Further, increased care and attention during itching/scratching may lead to reinforcement of the child's behavior.

\section{Role of Stress}

Physical or mental stress has an important role in immunoprotection, immunoregulation, and immunopathology in psychodermatological disorders and can lead to exacerbation of dermatoses. ${ }^{45,69}$ Neuroendocrine and neuroimmune dysregulations by stress are at the core of autoimmune or inflammatory dermatologic disorders which suggests a bidirectional relationship concept of psychosomatic disorders. ${ }^{70}$

Acute stress results in rapid physiologic response and release of glucocorticoids, catecholamines, and neuropeptides by the immune system which in turn leads to release of inflammatory mediators and cells. This is followed by rapid cessation of response after termination of stressful event. However, increased duration and magnitude of stress-releasing hormones, in chronic stress, innate, and adaptive immune function, get suppressed and dysregulation sets in. ${ }^{71,72}$

\section{Gut-Brain-Skin Interaction as Part of PSYCHONEUROENDOCRINE IMMUNOLOGY}

Gut and skin can be considered as integral parts of neuroendocrine and immune organs, ${ }^{73}$ and cytokines, neurohormones, neuropeptides, and other messengers have role in cellular signaling exchange in this gut-brain-skin axis. ${ }^{74}$ The concept of relation between psyche and skin via gut-brain-skin interaction, i.e., gut, psychological stress and mental processes, and skin are connected was explored. ${ }^{75}$ Here, reduction in lactobacilli and bifidobacteria in gut is linked with mental illness. A dysfunction in gut barrier can be result of psychological stress via glucocorticoids, subsequently dysfunction in microbiome leads to an enhanced uptake of proinflammatory mediators from the gut lumen; this process involves mast cells, which are considered pivotal cells in several psychodermatologic disorders, specifically, psychophysiological disorders. ${ }^{9,76,77}$

Both skin and intestinal mucosa secrete neuropeptides/ neurohormone, hormones (endocrine), cytokines (immune) and are in connection with other body organs and systems. Because of this, it appears that there is a state of physiological inflammation (normal phenomenon) both in skin and intestine. Skin and intestinal are constantly exposed microorganisms and antigenic charge, which will lead to a state of inflammation and this is an essential physiological process. ${ }^{74}$ Epithelial barrier disruptions, altered immune balance and homeostatic disruption can lead to disease onset by initiation of low grade chronic inflammation. ${ }^{74}$ Dermatoses like atopic dermatitis, vitiligo, and acne vulgaris are related to skin microbial changes and loss of physiological immunocompetence. ${ }^{76,78,79}$ Based on the psychoneuroendocrine immunologic concept, Lotti et al. had introduced an innovative approach of using low dose cytokine therapy to address acute and chronic cutaneous inflammatory diseases. ${ }^{80}$

The mechanisms for association between dermatoses and psychiatric disorders can be broadly understood as (1) dermatoses leading to stigma, social withdrawal and body image disturbances, which in turn cause psychological disorders/disturbances and (2) psychological stress leading to inflammation or systemic inflammation resulting in dermatoses and psychiatric disorders like depression. ${ }^{81}$

To summarize, following psychological comorbidities are seen with dermatoses, mostly inflammatory dermatoses:

- Behaviors seen in psychiatric disorders leading to skin lesions (e.g., chronic psychosis, depression resulting in poor self-care, and skin ulcerations)

- Dermatoses leading to psychological suffering (e.g., vitiligo resulting in stigmatization, social withdrawal, and depression)

- Common inflammatory cause manifesting I dermatoses and psychological disorder

- Purely psychiatric diseases like delusion of parasitosis or body dysmprophic disorder

- Heterogeneous group disorders like vulvodynia, chronic oral pain syndrome 


\section{Assessments}

Assessment tools routinely used in psychiatry for depression and anxiety are used in psychodermatology also. In addition, quality of life is assessed using dermatology life quality index. ${ }^{82}$ It is used to assess quality of life in dermatology patients above 16 years of age.It consists of 10 items and each item is rated on a 4-point Likert rating (0-3). The higher the scores, the greater the impairment on QoL.

\section{Management in Psychodermatology}

Comprehensive management of psychodermatologic disorders should be multipronged with inclusion of psychopharmaocological and psychological interventions. General approach is to assess the condition and assign it to the group in the classification of psychodermatologic disorder (e.g., dermatologic disorders with psychiatric symptoms, psychiatric disorders with dermatologic symptoms, or psychophysiological disorders). Then assess presence of symptoms or syndromal depression or anxiety or psychosis or obsession-compulsion and assess severity it. Finally, one has to make a comprehensive plan of treatment.

Dermatoses which are induced or worsened by psychological stress or psychological mechanism, and/or psychopathology as main elements, management should always begin with psychoeducation about role of psychological aspects in dermatoses with biopsychosocial underpinnings which will enable the patient to cope in a better way and have realistic goals. ${ }^{9}$ Depending on the syndromal diagnosis of anxiety, depression, obsessive compulsive disorder or psychosis, psychotropics should be considered as per the standard practice.

\section{Psychodermatology Clinic Models}

To address the specific subset of population requiring psychodermatological evaluation, liaison clinic with a team consisting of psychiatrist, dermatologist, and clinical psychologist will be ideal, which is followed in Kasturba Medical College, Manipal in India. ${ }^{49}$ However, with available resources, different models have shaped up consisting of psychiatrist alone, psychologist alone, dermatologist alone, psychiatrist, and dermatologist together, psychologist and dermatologist together, multidisciplinary team. ${ }^{83}$

\section{ConcLusion}

Psychodermatology or psychocutaneous medicine is conceptualized as integration of psychosocial aspects with cutaneous disorders with an increasing number studies highlighting the connection of the psychoneuroimmune-cutaneous-endocrine systems. The emphasis on relationship of stress and skin disorders with biological explanation has led to better understanding of the concept. Universally accepted definitions and classifications are still evolving with newer literature. Focused and intensive research on assessment and therapeutic approaches will aid treatment of psychodermatological conditions. Dedicated psychodermatology clinics are still in infancy in many countries; however, training programs can consider orientaing and preparing psychiatrists, dermatologists, and psychologists to evaluate and address psychosocial impact of dermatoses with an aim to improve quality of life of patients.

\section{ORCID}

Ravindra N Munoli ㄷ https://orcid.org/0000-0002-3419-2819

\section{References}

1. Schaller C. Die Haut alsGrenzorgan und Beziehungsfeld. In: Tress W (Hrsg) PsychosomatischeGrundversorgung, 2. Aufl. Stuttgart: Schattauer; 1997. p. S94-S96.

2. Sack T, 1928. In: Whitlock FA. Psychophysiological aspects of skin disease. London: WB Saunders Limited; 1976.

3. Anzieu D, Das Haut-IchAufl, Frankfurt AM: Suhrkamp Verlag; 1992.

4. Van Moffaert M. Psychodermatology: an overview. Psychother Psychosom 1992;58:125-136. DOI: 10.1159/000288621.

5. Gupta MA, Gupta AK, Ellis CN, et al. Psychiatric evaluation of the dermatology patient. Dermatol Clin 2005;23:591-599. DOI: 10.1016/ j.det.2005.05.005.

6. Gupta MA, Gupta AK. Psychodermatology: an update. J Am Acad Dermatol 1996;34:1030-1046. DOI: 10.1016/s0190-9622(96)90284-4.

7. Wessely SC, Lewis GH. The classification of psychiatric morbidity in attenders at a dermatology clinic. Br J Psychiatry 1989;155:686-691. DOI: 10.1192/s0007125000018201.

8. Koo J. Psychodermatology: a practical manual for clinicians. Curr Probl Dermatol 1995;7:203-225.DOI: 10.1016/S1040-0486(09)80012-4.

9. Jafferany M, Ferreira BR, Patel A. The essentials of psychodermatology. Cham, Switzerland: Springer International Publishing; 2020. p. 29-34.

10. Linthorst Homan MW, Spuls PI, de Korte J, et al. The burden of vitiligo: patient characteristics associated with quality of life. J Am Acad Dermato 2009;61:411-420. DOI: 10.1016/j.jaad.2009.03.022.

11. Linthorst Homan MW, de Korte J, Grootenhuis MA, et al. Impact of childhood vitiligo on adult life. Br J Dermatol 2008;159:915-920. DOI: 10.1111/j.1365-2133.2008.08788.x.

12. Cossidente A, Sarti MG. History and fundamentals of psychosomatic dermatology. Clin Dermatol 1984;2:1-16.DOI: 10.1016/0738081x(84)90042-7.

13. Poot F, Sampogna F, Onnis L. Basic knowledge in psychodermatology. J Eur Acad Dermatol Venereol 2007:21:227-234. DOI: 10.1111/j.14683083.2006.01910.x.

14. Shafii M, Shafii S. Exploratory psychotherapy in the treatment of psoriasis. Twelve hundred years ago. Arch Gen Psychiatry 1979;36:1242-1245. DOI: 10.1001/archpsyc.1979.01780110096012.

15. FrançaK,CastilloDE, Roccia MG, etal.Psychoneurocutaneous medicine: past, present and future. Wien Med Wochenschr2017;167:31-36. DOI: 10.1007/s10354-017-0573-3.

16. França K, Chacon A, Ledon J, et al. Psychodermatology: a trip through history. An Bras Dermatol2013;88:842-843. DOI: 10.1590/abd18064841.20132059.

17. Elangasinghe V, Lee KYC, Levell NJ. An historical account of dermatology in Buddhist Sri Lankan literature. Int J Dermatol2014;53:390-392. DOI: $10.1111 /$ ijd.12422.

18. Singh S, Tripathi JS, Rai NP. An overview of Ayurvedic \& contemporary approaches to psychodermatology. J Phytopharmacol2014; 3:286-299. http://www.phytopharmajournal.com/Vol3_Issue4_10.pdf

19. Rodríguez-Cerdeira C, Pera-Grasa J, Molares A, et al. Psychodermatology: past, present and future. Open Dermatol J2015;5:21-27. DOI: 10.1007/s10354-017-0573-3.

20. Koo JY, Pham CT. Psychodermatology. Practical guidelines on pharmacotherapy. Arch Dermatol 1992;128:381-388. DOI: 10.1001/ archderm.128.3.381.

21. Bjornsson AS, Didie ER, Phillips KA. Body dysmorphic disorder. Dialogues Clin Neurosci 2010;12(2):221-232.DOI: 10.31887/ DCNS.2010.12.2/abjornsson.

22. Freud S. The wolfman and other cases. London: Penguin Books; 2002.

23. Klauder JV. Syphilis and the characters in Ibsen's Dramas. Ann Med Hist 1936;8(3):236-241.

24. https://pdai.in/about.php[Last Accessed on 15 April 2021].

25. Shenoi SD, Prabhu S, Nirmal B, et al. Our experience in a psychodermatology liaison clinic at Manipal, India. Indian J Dermatol 2013;58:53-55. DOI: 10.4103/0019-5154.105310.

26. Brar BK, Brar SK, Puri N, et al. Psychodermatology liaison clinic at a tertiary care centre in North India. Sch J App Med Sci 2016;4:27952798.DOI:10.21276/sjams.2016.4.8.14. 
27. Bewley A, Magid M, Reichenberg JS, et al. Introduction. In: Bewley A, Taylor RE, Reichenberg JS, et al., editors. Practical psychodermatology. Chichester, UK: Wiley Blackwell; 2014. p. 3-10.

28. Reichenberg JS, Kroumpouzos G, Magid M. Approach to a psychodermatology patient.GItal Dermatol Venereol2018;153:494-496. DOI: 10.23736/S0392-0488.18.05965-5.

29. Koo JYM, Lee CS. General approach to evaluating psychodermatological disorders. In: Koo JYM, Lee CS, editors. Psychocutaneous medicine. Basic and clinical dermatology. New York, NY: Marcel Dekker; 2003. p.1-12.

30. Ferreira BR, Jafferany M, Patel A. Classification and terminology of psychodermatologic disorders. In: Jafferany M, Ferreira BR, Patel A, authors. The essentials of psychodermatology. Cham, Switzerland AG: Springer International Publishing; 2020. p. 37-46.

31. Ferreira BR, Jafferany M. Classification of psychodermatological disorders. J Cosmet Dermatol2021:1-3. DOI: 10.1111/jocd.14112

32. Tareen RS. Pediatric psychodermatology: a clinical manual of child and adolescent psychocutaneous disorders. Berlin: De Gruyter; 2013.

33. Jafferany M, França K. Geriatric psychodermatology:psychocutaneous disorders in the elderly. New York: Nova Science; 2015.

34. França K, Panchaprateep R, Tosti A. Optimal patient management of alopecia. Oxford: Gardner Healthcare Communications; 2015.

35. França K, Nouri K. Psycodermato-oncology: skin cancers in the elderly. In: Jafferany M, França K, editors. Geriatric psychodermatology: psychocutaneous disorders in the elderly. New York: Nova Science; 2015. p. 187-193.

36. Castillo D.E., França K., Lotti T. Psychological approach in cosmetic dermatology. In: Issa M, Tamura B, editors. Daily routine in cosmetic dermatology. Clinical approaches and procedures in cosmetic dermatology. Cham: Springer; 2016. DOI: 10.1007/978-3-319-202501_3-1 (Last accessed on 15 April 2021).

37. Tyring S, Lupi O, Hengge U. Tropical dermatology. Edinburgh: Churchill Livingstone; 2006.

38. Freiman A, Barankin B, Elpern D. Sports dermatology part 1: common dermatoses. Can Med Assoc J2004;171:851-853. DOI: 10.1503/ cmaj.1041143.

39. França K, França A, França R. Environmental psychodermatology: stress, environment and skin. In: França K, Jafferany M, editors. Stress and skin disorders. Heidelberg: Springer; 2017. p. 47-53.

40. Bolognia JL, Schaffer JV, Duncan KO, KoCJ. Dermatology essentials e-book. United States: Elsevier Health Sciences; 2014.

41. Gupta MA, Voorhees JJ. Psychosomatic dermatology: is it relevant? Arch Dermatol 1990;126:90-93. DOI: 10.1001/ archderm.1990.01670250096016.

42. Korabel H, Dudek D, Jaworek A, et al. Psychodermatology: psychological and psychiatrical aspects of dermatology. Przegl Lek2008;65:244-248. PMID: 18853651.

43. Turk T, Dytoc M, Youngson E, et al. Estimated frequency of psychodermatologic conditions in Alberta, Canada. J Cutan Med Surg 2021;25:30-37. DOI: 10.1177/1203475420952424.

44. Hu SCS, Chen GS, Tu HP. Epidemiology of depression in patients with psoriasis: a nationwide population-based crosssectional study. Acta Derm Venereol 2019;99:530-538. DOI:10.2340/00015555-3145.

45. Picardi A, Abeni D. Stressful life events and skin diseases: disentangling evidence from myth. Psychother Psychosom 2001;70:118-136. DOI: $10.1159 / 000056237$.

46. Colón EA, Popkin MK, Callies AL, et al. Lifetime prevalence of psychiatric disorders in patients with alopecia areata. Compr Psychiatry 1991;32:245-251. DOI: 10.1016/0010-440X(91)90045-E.

47. Yaghmaie P, Koudelka CW, Simpson EL. Mental health comorbidity in patients with atopic dermatitis. J Allergy Clin Immunol 2013;13: 428-433. DOI: 10.1016/j.jaci.2012.10.041.

48. Miniksar DY, Özcan ÖÖ, Cenk H, et al. Psychiatric morbidity in children and adolescents with dermatological disorders. Scand J Child Adolesc Psychiatr Psychol 2021;9:1-8. DOI: 10.21307/sjcapp-2021-001.
49. Goyal N, Shenoi S, Prabhu SS, et al. Psychodermatology liaison clinic in India: a working model. Trop Doct2018;48:7-11. DOI: $10.1177 / 0049475517736708$.

50. Raikhy S, Gautam S, Kanodia S. Pattern and prevalence of psychiatric disorders among patients attending dermatology OPD. Asian J Psychiatr 2017;29:85-88. DOI: 10.1016/j.ajp.2017.04.018.

51. Pulimood S, Rajagopalan B, Rajagopalan M, et al. Psychiatric morbidity among dermatology inpatients. Natl Med J India 1996;9:208-210.

52. Shenoi SD, Prabhu SS. Psychodermatology: an Indian perspective. Clin Dermatol 2018;36:737-742. DOI: 10.1016/j.clindermatol.2018.08.013.

53. Gaikwad R, Deshpande S, Raje S, et al. Evaluation of functional impairmentin psoriasis. Indian JDermatolVenereolLeprol2006;72:37-40. DOI: $10.4103 / 0378-6323.19716$.

54. Rakesh SV, D'Souza M, Sahai A. Quality of life in psoriasis: a study from south India. Indian J Dermatol VenereolLeprol 2008;74:600-606. DOI: $10.4103 / 0378-6323.45101$.

55. Chaudhury S, Das AL, John RT, et al. Psychological factors in psoriasis. Indian J Psychiatry 1998;40:295-299. PMID: 21494487; PMCID: PMC2966606.

56. Malhotra SK, Mehta V. Role of stressful life events in induction or exacerbation of psoriasis and chronic urticaria. Indian J Dermato Venereol Leprol 2008;74:594-599. DOI: 10.4103/0378-6323.45100.

57. Mattoo SK, Handa S, Kaur I, et al. Psychiatric morbidity in vitiligo: prevalence and correlates in India. J Eur Acad Dermatol Venereol2002;16:573-578. DOI: 10.1046/j.1468-3083.2002.00590.x.

58. Karia SB, De Sousa A, Shah N, et al. Psychiatric morbidity and quality of life in skin diseases: a comparison of alopecia areata and psoriasis. Ind Psychiatry J2015;24:125-128. DOI: 10.4103/09726748.181724.

59. Vallerand IA, Lewinson RT, Parsons LM, et al. Assessment of a bidirectional association between major depressive disorder and alopecia areata. JAMA Dermatol 2019;155:475-479. DOI: 10.1001/ jamadermatol.2018.4398.

60. Vallerand IA, Lewinson RT, Parsons LM, et al. Vitiligo and major depressive disorder: a bidirectional population-based cohort study. J Am Acad Dermatol 2019;80:1371-1379. DOI: 10.1016/j. jaad.2018.11.047.

61. Bharath S, Shamasundar C, Raghuram R, et al. Psychiatric morbidity in leprosy and psoriasis--a comparative study. Indian J Lepr1997;69: 341-346. PMID: 9474509.

62. Neerackal RJ, Abdul Latheef EN, Sukumarakurup S, et al. Relaxation therapy in the management of psoriasis. Dermatol Ther 2020;33:e14030. DOI: 10.1111/dth.14030.

63. Kumar V, Mattoo SK, Handa S. Psychiatric morbidity in pemphigus and psoriasis: A comparative study from India. Asian J Psychiatr 2013;6:151-156. DOI: 10.1016/j.ajp.2012.10.005.

64. Sarkar R, Raj $L$, Kaur $H$, et al. Psychological disturbances in Indian children with atopic eczema. J Dermatol2004;31:448-454. DOI: 10.1111/j.1346-8138.2004.tb00530.x

65. Malhotra S, Grover S, Baweja R, et al. Trichotillomania in children. Indian Pediatr 2008;45:403-405.

66. Detig-Kohler C. Hautnah: Impsychoanalytischen Dialog mitHautkranken. Giessen: Psychosozial Verlag; 2002.

67. Bick E. Hauterfahrung in frühen Objektbezieheung. Int J Psycho Anal 1968;49:484. PMID: 5698219.

68. Koblenzer C, Koblenzer P. Chronic intractable atopic eczema. Its occurrence as a physical sign of impaired parent-child relationships and psychologic development arrest: improvement through parent insight and education. Arch Dermatol 1988;124:1673-1677. DOI: 10.1001/archderm.124.11.1673.

69. Dhabhar FS. Psychological stress and immunoprotection vs. immunopathology in the skin. Clin Dermatol2013;31:18-30. DOI: 10.1016/j.clindermatol.2011.11.003.

70. Jafferany M, Patel A. Understanding psychocutaneous disease: psychosocial \&psychoneuroimmunologic perspectives. Int J Dermatol 2019;59:8-15. DOI: 10.1111/ijd.14629. 
71. Jafferany M, Salimi S, Mkhoyan R, et al. Psychological aspects of aesthetic and cosmetic surgery: clinical and therapeutic implications. Dermatol Ther 2020;33:e13727.DOI: 10.1111/dth.13727.

72. Hafi $B$, Uvais NA, Jafferany $M$, et al. Palliative psychodermatology care during COVID-19 pandemic. Dermatol Ther 2020;33:e13732. DOI: $10.1111 /$ dth. 13732 .

73. O'Neill CA, Monteleone G, McLaughlin JT, et al. The gut-skin axis in health and disease: a paradigm with therapeutic implications. Bio Essays 2016;38:1167-1176. DOI: 10.1002/bies.201600008.

74. França K, Lotti TM. Psycho-neuro-endocrine-immunology: apsychobiological concept. Adv Exp Med Biol 2017;996:123-134. DOI: 10.1007/978-3-319-56017-5_11.

75. Arck P, Handjiski $B$, Hagen $E$, et al. Is there a 'gut-brain-skin axis'? Exp Dermatol 2010;19:401-405.DOI: 10.1111/j.1600-0625.2009.01 060.x.

76. Bowe WP, Logan AC. Acne vulgaris, probiotics and the gut-brain-skin axis—back to the future? Gut Pathog 2011;3:1. DOI: 10.1186/17574749-3-1

77. Soderholm JD, Perdue MH. Stress and gastrointestinal tract. II. Stress and intestinal barrier function. Am J Physiol Gastrointest Liver Physiol 2001;280:G7-G13.DOI: 10.1152/ajpgi.2001.280.1.G7.
78. Myles IA, Williams KW, Reckhow JD, et al. Transplantation of human skin microbiota in models of atopic dermatitis. JCl Insight 2016;7;1:e86955. DOI: 10.1172/jci.insight.86955.

79. Ganju P, Nagpal S, Mohammed MH, et al. Microbial community profiling shows dysbiosis in the lesional skin of Vitiligo subjects. Sci Rep 2016;13;6:18761. DOI: 10.1038/srep18761.

80. Lotti T, Hercogova J, Wollina U, et al. Psycho-neuro-endocrineimmunology and low dose cytokines therapy: principles and evidences for an innovative medical approach in acute and chronic inflammatory diseases. J Biol RegulHomeost Agents 2015;29 (1 Suppl):37-45. PMID: 26016967.

81. Toups M. Inflammation and depression: the neuroimmune connection. Curr Treat Options Psychiatry 2018;5:452-458. DOI: 10.1007/s40501-018-0157-x.

82. Finlay AY, Khan GK. Dermatology life quality index (DLQI)—a simple practical measure for routine clinical use. Clin Exp Dermatol1994;19:210-216. DOI: 10.1111/j.1365-2230.1994.tb01167.x.

83. Patel A, Jafferany M. Multidisciplinary and holistic models of care for patients with dermatologic disease and psychosocial comorbidity: a systematic review. JAMA Dermatol 2020;156:686-694. DOI: 10.1001/ jamadermatol.2020.0394. 